\title{
КОНФЛИКТ СОБСТВЕННОСТИ В УСТОЙЧИВОМ РАЗВИТИИ
}

\author{
(c) 2021 Кивуля Дарья Сергеевна \\ преподаватель, кафедра «Экономическая теория» \\ Белорусская государственная сельскохозяйственная академия, Республика Беларусь, Горки \\ E-mail: d_kivulya@baa.by
}

В статье обосновывается наличие конфликта собственности в устойчивом развитии между поколениями. Представлена методика позитивного анализа структуры поколения настоящего по уровням межпоколенческой солидарности, позволяющая выявить качественный и количественный состав поколения настоящего, определить соответствие присвоения природных ресурсов рамкам концепций CHM (общего наследия человечества) SD (устойчивого развития). Преодоление конфликта собственности в устойчивом развитии достигается через производство глобальных общественных благ и повышение эффективности использования природного капитала. Обосновывается авторский показатель - интегральный индекс эффективности использования природного капитала.

Ключевые слова: конфликт собственности, устойчивое развитие, присвоение, общемировые блага, глобальные ресурсы общего доступа, межпоколенческая солидарность, социальная эффективность, природный капитал.

Концепция общего наследия человечества задает направление развития новой формы присвоения на наднациональном уровне: «на благо человечества... в интересах будущих поколений» [5]. Подобные мысли высказываются и в концепции устойчивого развития: «... не уменьшая возможностей использования будущими поколениями» [9]. Концепция планетарной собственности $[1,2]$, т.е. присвоения общемировых благ, возникла и развивается на базе двух концепций: правовой (CHM) и экономико-теоретической (Sustainable Development - SD). В то же время право, как формальный институт определяет поведение экономических агентов, оно также выступает объектом изучения институциональной экономической теории. Следовательно, как юридическая, так и экономическая составляющие планетарной собственности находятся в русле экономико-теоретических исследований.

В книге С.Мура «Альтернативные пути к устойчивому городу» автором определяется наличие конфликта собственности в устойчивом развитии города, как конфликта интересов собственников средств производства, и тех, в чью пользу будет производиться перераспределение результатов этого производства [8]. Анализ С. Мура может быть распространен и на глобальное общество.

Поколение настоящего (present generation PG) монопольно присваивает GCPR (глобальные ресурсы общего доступа - общемировые блага), поскольку поколение будущего (future generation - FG) не имеет возможности потреблять GCPR, или оказывать влияние на действия PG. Являясь фактическим пользователем GCPR, PG несет ответственность за свои действия перед FG, исходя из принципов CHМ, закрепленных в международном праве. Однако PG не однородно по своему составу в части соблюдения международных договоренностей и норм международного права. Преследуя личный интерес (минимизируя издержки и максимизируя выгоды), присваивая общемировые блага, PG сокращает возможности FG.

Решение конфликта собственности достигается при производстве GPG (глобальных общественных благ), когда совместные усилия мирового сообщества, направленные на сохранение GCPR, позволяют этим системам ресурсов функционировать в неизменном состоянии, и присутствует некоторое равенство возможностей PG и FG в удовлетворении своих потребностей. В данном случае не сами общемировые блага выступают как GPG, а результаты их функционирования - экосистемные услуги: стабильность климата, сохранение биоразнообразия, ассимиляционный потенциал и др. Необходимо отметить, что именно производство GPG является приоритетом для сохранения GCPR. Экономическое присвоение поколения настоящего сопровождается экстерналиями. Домохозяйства, фирмы, государства, производя и потребляя, 
присваивают общемировые блага возрастающими темпами. Следовательно, присвоенные ими блага уже не могут быть задействованы в воспроизводственном процессе системы. Действия, направленные на сокращение темпов присвоения общемировых благ доступны каждому субъекту хозяйствования, такие действия способствуют индивидуальному производству GPG.

Другой подход основывается на выборе между текущим потреблением, и потреблением будущего. Как известно, инвестиции в капитал являются примером отказа от текущего потребления в пользу будущих доходов. Концепция природного капитала может позволить приблизиться к осуществлению количественной оценки эффективности использования природной составляющей планетарной собственности.

Г.Дэйли предоставил альтернативную экономическую структуру «природного капитала», находя в нем подобие понятию финансового капитала, поскольку природный капитал приносит доход, он предложил следующее его определение: «Природный капитал - запас, который порождает поток природных ресурсов - популяции рыбы в океане, которые восстанавливают себя после отлова их части для потребления; многолетний лес, который восстанавливает свои площади после вырубки, пожара без участия людей; запас нефти...» [6].

Категория «природный капитал» используется при анализе экономики конкретной страны. Для характеристики природных ресурсов глобального уровня нами был предложен термин «природный планетарный капитал» (NPC) - запас естественных ресурсов и экосистемных услуг планеты Земля. Природный планетарный капитал подразделяется на возобновляемый - PRNC (характеризующийся свойствами воспроизводства и приумножения) и невозобновляемый PNNC (при потреблении которого первоначальное вещество отчуждается и трансформируется).

Формирование «запаса» общемировых благ или планетарного природного капитала, как условия благосостояния мирового сообщества в долгосрочной перспективе, ответственное их использование и рациональное экономическое присвоение, не уменьшающее возможностей поколения будущего, соответствует критерию межпоколенческой солидарности. Сокращение потребления невозобновляемого планетарного природного капитала, за счет потребления возобновляемого, также способствует достижению межпоколенческой солидарности. Социальная эффективность в долгосрочном периоде заключается в обеспечении равенства возможностей для удовлетворения потребностей всех поколений: как PG так и FG.

Согласно концепциям CHM и SD, присвоение поколением настоящего не должно уменьшать возможностей поколения будущего на удовлетворение своих потребностей. Такое присвоение должно основываться на критерии межпоколенческой солидарности. Критерий межпоколенческой солидарности определяет социальную эффективность в долгосрочном периоде: обеспеченность общемировыми благами будущих поколений [7].

На пути к достижению межпоколенческой солидарности возникает дилемма выбора между текущим потреблением, и потреблением будущего. Человечеству предстоит выработать такой механизм реализации прав собственности на общемировые блага, чтобы использование этих систем ресурсов не приводило к ухудшению их качества.

Межпоколенческая солидарность может различаться в зависимости от уровня распространения. Автором выделяется три уровня:

1. Солидарность в рамках одного поколения - когда обеспечение равных возможностей на удовлетворение своих потребностей происходит в данный конкретный промежуток времени.

2. Межпоколенческая солидарность в рамках одной страны - равенство возможностей по удовлетворению потребностей на национальном уровне в долгосрочной перспективе.

3. Универсальная межпоколенческая солидарность - общечеловеческие ценности становятся более приоритетными, чем национальные.

Если рассматривать субъекты отношений планетарной собственности в долгосрочном периоде, то, исходя из концепций CHM и SD, можно выделить субъект «поколение настоящего» - PG и «поколение будущего» - FG. Между данными субъектами реализуются отношения присвоения/отчуждения. Потребление поколения настоящего уменьшает возможности поколения будущего удовлетворять свои потребности, обеспечиваемые главным образом за счет потребления невозобновляемого природного капитала. Напротив, долгосрочная стратегия поведения субъекта поколение настоящего позволяет достичь некоторой степени межпоко- 
ленческой солидарности, как фактора повышения социальной эффективности в долгосрочном периоде.

Тогда зависимость потребления общемировых благ в долгосрочном периоде приняла вид:

$$
F G=(P N N C+P R N C+\beta)-P G ;
$$

где FG - потребление поколения будущего, PG - потребление поколения настоящего, PNNC - невозобновляемый планетарный природный капитал, PRNC - возобновляемый планетарный природный капитал, $\beta$ - прирост возобновляемого природного капитала, определяется стратегией поведения акторов.

Поколение настоящего и поколение будущего вместе образуют субъект международного права - человечество Н.

\section{$P G \cup F G \in H$}

Монопольное присвоение элементов общемировых благ поколением настоящего происходит на всех уровнях экономического анализа. Поколение настоящего в своём составе не однородно и различается по уровням межпоколенческой солидарности.

$$
P G^{*} \cup P G^{\prime} \cup P G^{\prime \prime} \in P G
$$

Универсальная межпоколенческая солидарность.

$$
\mathrm{U}_{\mathrm{PG}^{*}}=\mathrm{f}\left(\mathrm{PNNC}, \mathrm{PRNC}, \mathrm{U}_{\mathrm{FG}}\right)
$$

Межпоколенческая солидарность в рамках одной страны.

$$
\mathrm{U}_{\mathrm{PG}},=\mathrm{f}\left(\mathrm{PNNC}, \mathrm{PRNC}, \mathrm{U}_{\mathrm{FG}}\right)
$$

Межпоколенческая солидарность в раках одного поколения.

$$
\mathrm{U}_{\mathrm{PG} \prime \prime}=\mathrm{f}(\mathrm{PNNC}, \mathrm{PRNC})
$$

Нами предложен методологический подход к оценке эффективности использования природного капитала с позиции триединства «человек-природа-общество» [3, 4]. В общем виде интегральный индекс эффективности использования природного капитала может быть представлен формулой (7):

$$
\frac{\mathrm{I}_{\mathrm{ENCU}}=\sqrt[16]{\mathrm{I}_{\mathrm{CY}} \cdot \mathrm{I}_{\mathrm{AL}} \cdot \mathrm{I}_{\mathrm{FA}} \cdot \mathrm{I}_{\mathrm{SA}} \cdot \mathrm{I}_{\mathrm{EN}} \cdot \mathrm{I}_{\mathrm{RR}} \cdot \mathrm{I}_{\mathrm{EF}} \cdot \mathrm{I}_{\mathrm{EI}}}}{\mathrm{I}_{\mathrm{CW}} \cdot \mathrm{I}_{\mathrm{EG}} \cdot \mathrm{I}_{\mathrm{CR}} \cdot \mathrm{I}_{\mathrm{EA}} \cdot \mathrm{I}_{\mathrm{CE}} \cdot \mathrm{I}_{\mathrm{GA}} \cdot \mathrm{I}_{\mathrm{CD}} \cdot \mathrm{I}_{\mathrm{PA}}}
$$

где CY - урожайность зерновых (кг/га),

$\mathrm{AL}$ - площадь c/x земель (\% от общей площади),

$\mathrm{FA}$ - площадь леса (\% от общей площади),

SA - доля продукции сельского хозяйства (\% от ВВП),

$\mathrm{EN}-$ экспорт руд и металлов (\% от экспорта),

$\mathrm{RR}$ - доходы от природных ресурсов (\% от ВВП),

$\mathrm{EF}$ - экспорт топлива (\% от экспорта),

EI - чистый импорт энергии (\% от потребляемой энергии),

$\mathrm{CW}$ - ежегодный забор пресной воды (\% от внутренних источников),

EG - выбросы CO2 (кг на душу населения),

$\mathrm{CR}$ - потребление возобновляемой энергии

(\% от конечного потребления),

EA - доступ к электроэнергии (\% населения),

CE - потребление электроэнергии на душу населения (кВт/чел.)

GA - условия жизни, соответствующие санитарным требованиям (\% населения),

CD - смертность в возрасте до 5 лет,

PA - рост численности населения,

В основу определения эффективности использования природного капитала положен метод многомерного анализа. Суть метода состоит в поведении анализа оценки уровня эффективности использования природного капитала по совокупности выбранных показателей. Многомерный анализ широко используется в практике межстрановых сравнений. В основу расчета положены числовые показатели, взятые из официальных статистических источников (баз данных Всемирного Банка). Исходя из этого, алгоритм относительно объективен и поддается верификации.

Для решения задачи квантификации уровней межпоколенческой солидарности разделим совокупность стран на 3 группы по значению интегрального индекса эффективности использования природного капитала. В составе субъекта PG на начало исследуемого периода преобладали страны с династическим уровнем межпоколенческой солидарности, что соответствует значению индекса в среднем от 0,04 до 0,2. 


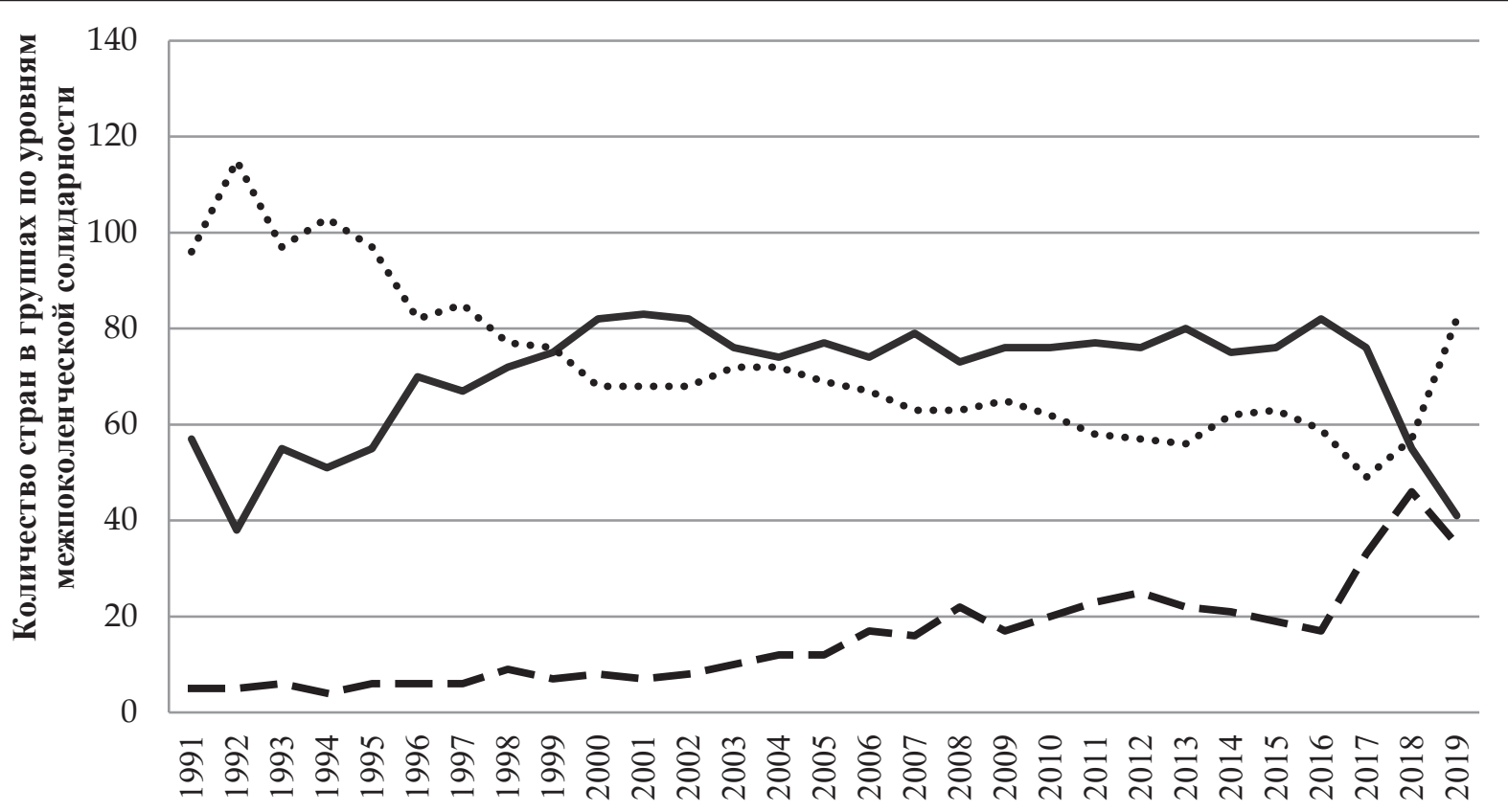

— - Универсальная межпоколенческая солидарность

— Национальная межпоколенческая солидарность

...... Династическая межпоколенческая солидарность

Рисунок 1. Количественное изменение состава PG по уровням межпоколенческой солидарности 1991-2019 гг.

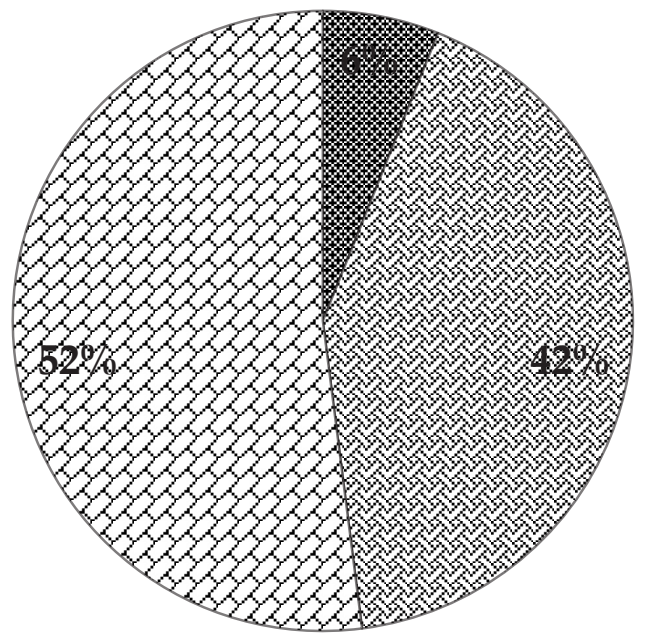

Универсальная межпоколенческая солидарность

\section{凶 Национальная} медпоколенческая солидарность

\section{จ Династическая межпоколенческая солидарность}

Рисунок 2. Структура PG по уровням межпоколенческой солидарности (среднее значение ENCU за период 1990-2019 гг.)

Состав группы стран с универсальной межпоколенческой солидарностью не изменялся до 2005 года и колебался вокруг 20 стран с 2005 по 2017 годы. После чего число стран, входящих в эту группу стало расти, достигнув максимума в 2018 году - 45 стран. Основные изменения в качественном составе PG происходили в 2 и 3 группах. Начиная с 1999 года, наблюдается пре- вышение числа стран с национальным уровнем межпоколенческой солидарности над числом стран в группе династической межпоколенческой солидарности.

Анализ значений интегрального индекса эффективности использования природного капитала, позволил выделить 3 группы стран в составе субъекта планетарной собственности PG. 
Данные расчетов интегрального индекса свидетельствуют о преобладании стран с краткосрочным временным горизонтом в составе субъекта планетарной собственности PG (династическая межпоколенческая солидарность) - 52\%. Наименьшую долю в составе PG имеют страны с долгосрочным временным горизонтом $-6 \%$.

В первую группу в 2019 году вошли 35 стран: Норвегия, Канада и Австралия на протяжении всего исследуемого периода входили в первую группу по индикатору межпоколенческой солидарности. Максимальные значения интегрального индекса позволяют отнести данные страны к уровню универсальной межпоколенческой солидарности. Во вторую группу вошли 40 стран: часть ЕС, Израиль, Корея, Япония. Данные страны относятся к уровню национальной межпоколенческой солидарности. К уровню династической межпоколенческой солидарности относятся 80 стран исследуемой совокупности.
Выводы.

Нами обобщены подходы к присвоению общемировых благ как GPG и NPC и предложен авторский критерий социальной эффективности в долгосрочном периоде - межпоколенческая солидарность. Проведенное исследование уровней межпоколенческой солидарности позволило выделить в составе субъекта планетарной собственности PG 3 группы стран. Страны уровня универсальной межпоколенческой солидарности осуществляют присвоение элементов общемировых благ, не создавая конфликта собственности в устойчивом развитии, таким образом, что возможности FG по удовлетворению своих потребностей не уменьшаются. Группа стран уровня династической и национальной межпоколенческой солидарности нуждается в корректировки стимулов для преодоления конфликта собственности в устойчивом развитии.

\section{Библиографический список}

1. Безгодов, А. В. Планетарный проект: от устойчивого развития к управляемой гармонии / А. В.Безгодов.СПб.: Питер, 2016.- 272 с.

2. Жадан, И.Э. Концепция экономики благосостояния: планетарная модель и особенности ее реализации в России: автореф. дис. ... д-ра экон. наук: 08.00.01 / И. Э. Жадан; Сарат. гос. соц.-экон. ун-т. - Саратов, 2010.$41 \mathrm{c.}$

3. Кивуля, Д. С. Теоретико-методологический подход к исследованию планетарной собственности / Д. С. Кивуля // Новая экономика. - 2019. - № 1.- С. 182-187.

4. Кивуля, Д. С. Эффективность использования природного капитала / Д.С. Кивуля // Новая экономика.2019. - № 1.- С. 276-282.

5. Пащенко, И. Ю. Концепция общего наследия человечества в современном международном праве и проблемы ее реализации / И. Ю. Пащенко // Science time. - 2014. - № 2. - С. 50-55.

6. Daly, $H$. Towards Some Operational Principles of Sustainable Development / H. Daly // Ecological Economics. 1990. - № 2.- P. 1-6.

7. Chichilnisky, G. Managing unknown risks / G. Chichilnisky, G. Heal // Journal of Portfolio Management. - 1998. - T. 24, № 4. - S. 85-91.

8. Moore, S. A. Alternative Routes to the Sustainable City: Austin, Curitiba, and Frankfurt / S. A. Moore.- Lanham: Lexington Books, 2007.- 262 p.

9. World Commission on Environment and Development (1987). Our Common Future.- Oxford: Oxford Univ. Press, 1987. $-27 \mathrm{p}$. 